\title{
Io. Facilitative Factors and Impediments to Newcomer Youth's Initial Integration Milestones: The Arab Newcomer Youth Experience
}

RIHAM AL-SAADI

\begin{abstract}
Within the Syrian refugees' initiative, Canada has adopted a leading role in welcoming a significant number of Syrian refugees, over 1,600 of which have settled in Windsor-Essex. This signifies the importance of enhancing our role as a host society in fostering opportunities that would lead Syrians to a successful integration. This book chapter consults literature on acculturation as well as facilitative factors and impediments that influence immigrants and refugees' integration.Integration is the strategy characterized by individuals or groups who are interested in maintaining their cultural heritage while establishing interactions with the larger society (Behrens, del Pozo, Großhennig, Sieberer, \& Graef-Calliess, 2015; Berry, 2001, 2005, 2014; Paterson, 2008). The chapter also highlights the importance of incorporating youth's perspectives to understand their integration experience. The stories of three youth present examples where youths' motive for achieving potential combined with formal and informal supports can facilitate initial integration milestones. Engaging youth voices can be used as a means of healing by drawing on their perspectives, thereby, youth are acknowledged and valued. Consequently, reconciliation is an anticipated outcome through social integration opportunities that the host (Canadian) society can help foster.
\end{abstract}


Key Terms: Acculturation, Integration, Syrian youth, Healing, Reconciliation, Immigrants, Refugees.

Special Appreciation to three powerful, inspiring, Syrian newcomer youth for their contributions to the knowledge and insight in this book chapter: Naeem A., Kheder A., Evin S.

Youth out of war bring a lot of potential; it is our job in the welcoming country to ensure that they are not wasted.

This chapter discusses integration experiences of Syrian (Arab) youth into their new, Canadian society. The overarching goal is to consult theoretical and anecdotal evidence to inform ways in which successful integration can be facilitated among Syrian and Arab youth. Cultural studies on integration and the acculturation process for immigrants and refugees have been greatly shaping the interest of theorists in social sciences fields (Berry, 2005, 2013; Paterson, 2008; Sabatier \& Berry, 2008; Vineberg, 2011). Canada, a lead nation in welcoming newcomers, is well positioned for such cultural studies to be conducted from, and the implications could significantly contribute to research and practice. Locally, Windsor and Essex County is highly diverse and is a welcoming community for immigrants and refugees from diverse ethnic backgrounds. According to recent statistics, 1 in 4 residents in Windsor-Essex is an immigrant, and Windsor-Essex has welcomed about 11,000 refugees between 2011 and 2016 (Windsor Essex Immigration, n.d.). Windsor-Essex's role in the Syrian refugees' initiative is one prime example of its welcoming nature. As part of the Local Immigration Partnership, five sectoral tables were formed in preparation to welcoming Syrian refugees; namely, health, settlement, education, housing, and welcoming communities. Since 2015, Windsor has been a recipient of 1,600 Syrian refugees (Immigration, Refugees and Citizenship Canada, 2017). This signifies the importance of investigating Syrian refugees' settlement and integration, and our contributions as academics or professionals in enhancing these experiences.

The prime goal of bridging literature with practical examples is to define facilitative and challenging factors influencing initial integration milestones. Integration is a long-term process that requires efforts from both host and heritage communities (Behrens, del Pozo, Großhennig, Sieberer, \& Graef- 
Calliess, 2015; Berry, 2005, 2013; Berry \& Kalin, 1995; Berry, Phinney, Sam, \& Vedder, 2006b). Therefore, considering the experiences consulted are from recent settlers, the knowledge gained may inform initial milestones in integration rather than speak to the long-term outcomes.

In this book chapter, I highlight the importance of incorporating youth's perspectives when attempting to understand their acculturation or integration experience, or when working with them to facilitate their integration in their new community. From a strength-based approach, engaging youth voices can be used as a means of healing by drawing on their perspectives. By doing so, youth are acknowledged and valued, thereby leading progressively to their successful integration into the host community.

There is a consensus among settlement agencies that youth tend to underutilize available programs and services they offer. While it is undeniable that a multitude of youth programs exist, there is a lack of youth's voices in decision-making surrounding youth programs' design and implementation as well as advocacy efforts; this tends to be quite restrictive. Empowering youth through acknowledging the importance of their perspective is one facilitative step towards their healing. Similarly, the lack of integration of their voices in programs and services that are meant to be of benefit to them stands as a barrier towards their integration. In striving to enhance refugee youth's active involvement in their new community, we (that is academics, professionals, and youth allies) would be progressively contributing to their healing. Stemming from this approach and in efforts to support Syrian youth in taking a lead role in their healing and reconciliation, I consulted the stories of three Syrian newcomer youth residing in the Windsor community. Through research and youths' lived experiences, I seek to answer the following questions: how are Arab newcomer youth actively engaged in their community, and how does their involvement facilitate their integration and progressively lead to their healing and reconciliation? Healing is anticipated to result from enhancements at the individual/ psychological level and reconciliation is anticipated to be facilitated through social integration opportunities led by their host (Canadian) society. Naeem A. shared how separation from his family can be a driving force rather than an impediment, Kheder A. continued (continues) to fulfill his educational aspirations, and Evin S. shares how her active involvement in various youth programs and extracurricular activities is fulfilling her aspirations. 


\section{MCC: A Key Player in the Lives of Refugees in Windsor-Essex}

The Multicultural Council of Windsor Essex (MCC) is an agency that holds a lead role in the facilitation of the settlement process among refugees in Windsor-Essex (Multicultural Council of Windsor Essex, n.d.). It serves as an avenue for newcomers to Windsor-Essex, meeting barriers with empowering steps, facilitating engagement, and creating a welcoming community for all. The MCC fulfills its mission through housing multiple supportive systems to address resettlement impediments among immigrants and refugees (Multicultural Council of Windsor Essex, n.d.). Its mission statement is, "The MCC creates a welcoming community for all through education, community engagement and the promotion of diversity and equality" (The Multicultural Council of Windsor Essex, n.d.). A wide range of immigrant populations are served through $\mathrm{MCC}$, all with different immigration statuses, demographics, and cultural backgrounds, with Government Assisted Refugees (GAR) being a focal point. Among the multitude of efforts are a few youth programs and services aimed at facilitating youth's potential achievement.

MCC has been a strong partnering community agency to the Tikkun Youth Project; its role in facilitating the healing and reconciliation among Syrian refugee youth does not go unnoticed. The three case examples demonstrate successful contributions that the MCC has played as a host society member in not only welcoming newcomer youth, but also valuing and fostering their potential. The examples further aid in presenting a closer insight into the Syrian refugee youth story, whose escape from their war-torn homeland has been an element of growth.

\section{Canada's Role in Multiculturalism}

Canada's efforts and international position as the first country to foster and adopt a policy of multiculturalism has been recognized internationally (Berry, Kim, Power, Young, \& Bujaki, 1989; Ng \& Metz, 2015), and has contributed to its unique stance globally as a land of attraction for immigrants from all backgrounds looking to attain prosperity economically, 
educationally and socially (Berry, 2013; Berry et al., 1989; Ng \& Bloemraad, 2015; Ng \& Metz, 2015; Vineberg, 2011). Universally, immigration patterns have drastically increased; Canada currently ranks as the seventh destination of immigration. As per a United Nations source, from 1960 to 2015, Canada has been a recipient of about 8 million immigrants, and they now constitute about 22\% of the total population (Migration Policy Institute, 2015). More recently, on November 1, 2017, Immigration Refugee and Citizenship Canada (2017) launched its immigration levels targets for 2018 to 2020, communicating its plan to welcome about one million immigrants and refugees to Canada. This calls for the importance of understanding the settlement and integration processes that immigrants and refugees undergo; it contributes to furthering the power of a multicultural society as ours.

\section{Integration, an Acculturation Strategy: The Process and the Outcomes}

Acculturation has been integral to the study of immigration processes and outcomes. Acculturation is defined as the process of psychological and cultural changes on both individual and group levels, often resulting from direct and constant contact between two or more distinct cultures (Berry, 1992, 2005, 2006, 2014; Berry, Phinney, Sam, \& Vedder, 2006a).

Influence on both cultures. Acculturation is influenced by the interplay of exchanged information between the host culture and the immigrant, or heritage culture (Berry, 1997, 2005, 2006, 2014). The cultural change that the group and the individuals in each group undergo is based on addressing two important aspects: 1) the value placed on maintaining one's ethnic culture; and, 2) the value placed on establishing and strengthening interethnic interactions with the larger society (Behrens et al., 2015; Berry, 1997, 2008, 2014; Sam, Vedder, Liebkind, Neto, \& Virta, 2008). The intersection of value placed on maintaining heritage by participating in the larger society results in a fourfold model of acculturation strategies. The four strategies defined from the ethnic group's perspective are interdependent and based on the larger society's approach to immigration and promotion of diversity. Figure 1 represents the strategies from the ethno-cultural and larger society's view, respectively. A positive or negative orientation towards each culture is symbolized with the positive and negative signs in Figure 1.

Facilitative Factors and Impediments to Newcomer Youth's Initial Integration Milestones | 246 


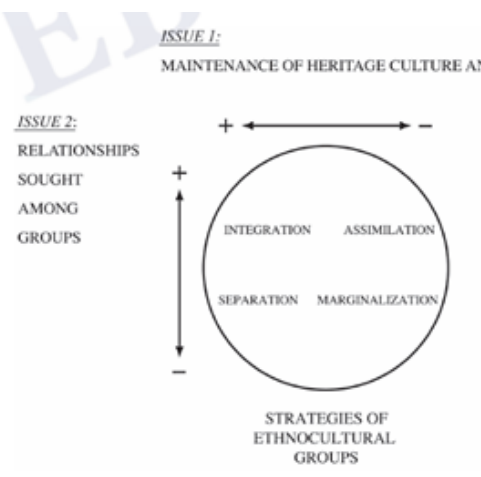

Figure 1. Four acculturation strategies from the ethnic and larger society's perspectives (Berry, 2005).

Integration. Integration is the strategy characterized by individuals or groups who are interested in maintaining their cultural heritage while establishing interactions with the larger society (Behrens et al., 2015; Berry, 2001, 2005, 2014; Paterson, 2008). Within integration, "some degree of cultural integrity is maintained, while at the same time immigrants seek, as a member of an ethno-cultural group, to participate as an integral part of the larger society" (Berry, 2005, p. 705). Integration is viewed as the most adaptive because it allows immigrant groups to maintain their heritage and culture, thereby enhancing their sense of empowerment and cultural identity, which, in turn, facilitates developing relations with the host community (Berry, 2001, 2006, 2013; Sam \& Berry, 2010). Furthermore, establishing contact and enhancing participation within the larger society gives one a greater sense of belonging, higher self-esteem, and further involvement with and awareness of existent social, employment, and academic opportunities (Behrens et al, 2015; Berry, 2006, 2013; Hui, Chen, Leung, \& Berry, 2015; Sabatier \& Berry, 2008).

Although integration is identified as the most adaptive strategy on both psychological and sociocultural levels, it is important that the dominant society hold a positive multicultural ideology for ethnic groups to integrate successfully (Berry, 2001, 2005; Berry \& Kalin, 1995; Hui et al., 2015). A descriptive for a positive multicultural attitude depicts that the host, or dominant, society values, promotes, and supports diversity as a core feature of their society, thereby supporting the integration of other heritage groups (Berry, 2001, 2013; Berry \& Kalin, 1995). Canada's immigration approach is

247 | Facilitative Factors and Impediments to Newcomer Youth's Initial Integration Milestones 
believed to be shaped by a positive multicultural ideology, generally shaped by its enactment of the Multiculturalism Act and continual welcoming of immigrants and refugees as depicted by its recent immigration plans; this is believed to be supportive of the multiculturalism approach (Berry, 2001, 2013; Berry \& Kalin, 1995; Immigration, Refugees and Citizenship Canada, 2017). In this case, a positive multicultural ideology acts as an element of healing from the pre-immigration traumatic impacts that refugee youth may have.

Acceptance and respective sharing of cultures communicates to youth the possibility of relief from their negative experiences. It also demonstrates that the possibility of reestablishing oneself in the new society, without risking the loss of heritage, is a reality that can be achieved. One way that a host society can facilitate this process is through fostering youth engagement. As both Kheder and Evin depict, their engagement in volunteerism acts as a medium for them to not only enhance their bonding with their new Canadian society, but also to showcase what they bring from their heritage, as well as to educate about and maintain their cultural values, an integral goal that each of them held.

Role of the dominantsociety. The perception of the impact of immigration on the dominant society also has a significant influence on whether multiculturalism and integration would be supported and promoted. If the sense of competition over existent resources, like jobs, is high, then multiculturalism will not be supported (Berry, 2001, 2005, 2006; Palmer, 1996).Likewise, if the dominant group senses a threat to maintaining the powerful status of their dominant ideologies on a societal level, then embracing alternate ideologies may not be favored, thereby inhibiting integration (Berry, 1997, 2006; Berry \& Kalin, 1995; Berry et al., 1989; Berry \& Sabatier, 2010; Palmer, 1996; Sabatier \& Berry, 2008).

Ontario vs. Quebec approaches. In a comparison of the most highly populated provinces in Canada, Ontario and Quebec, Laxer (2013) explains that each province's multicultural ideology, shaped by their policy, influences the nature of integration among immigrant groups. In Ontario, the Multiculturalism policy established in 1971 is implemented where multiple distinct cultures can exist together and shape a diverse, yet cohesive community. Alternately, Quebec has exclusive power over its implementation of immigration policies through their Quebec-Canada Accord of 1991 (Laxer, 2013). This approach dictates an integration discourse of inter-culturalism, where immigrants' participation is welcomed and 
encouraged, but is expected to abide to a "common public culture" (Laxer, 2013, p. 1581). For Quebec, it is important to acknowledge that the Francophone culture is not as dominant as Anglophones in Canada. Thus, any potential change to their composition may be viewed as a threat to the French culture (Berry \& Kalin, 1995).

Empirical research has examined Canadian attitudes towards the enactment of multiculturalism, and it will be further discussed (Berry \& Kalin, 1995). If we foster youth's growth and full participation in the new society, this will translate to the encouragement of youth to contribute equally in return. As one of the Windsor youth, Kheder, indicates, "This made me feel that I'm a good citizen for Canada. I do whatever I can to make people happy. Canada encourages socializing and that's what I would like to do and be part of people here."

Role of the cultural/immigrant group. It is important that the immigrant group is open to learning new values and the cultural practices of the host society, and attempt to adopt both (Behrens et al., 2015; Berry, 2006; Berry \& Sabatier, 2010; Sabatier \& Berry, 2008). The intention is not to encourage replacing their heritage; rather, it is meant to expand and complement this with new knowledge (Behrens et al., 2015; Berry, 2006; Berry \& Sabatier, 2010; Hui et al., 2015; Sabatier \& Berry, 2008). One of the contributing Syrian youth to this chapter, Evin, has shared that she sometimes continues to be bound by cultural expectations where she feels that adopting new values and cultural practices may not be a supported practice by her heritage culture. Evin shares, "I want to live normally, and I don't want to be tightly held by cultural expectations." She believes that her family's support for her goals may help her overcome the possible potential challenge of her heritage cultural expectations.

\section{Arab Youth Acculturation Experiences}

\section{Family Relations: The Importance of Family in Arab Culture}

Though it is difficult to quantify the importance of family, in the Arab 
community, family holds an esteemed place, and its structure is different as extended family members tend to have an active and influential role on the family structure. As Britto and Amer (2007) argue, family is considered the main social support resource and most important societal unit within the Arab community. Sometimes, due to their prioritization as a social support resource, maintaining relations takes precedence over individual needs and may come at the expense of making friends. This is consistent with findings offered by Daniel (2013), who notes that peer relations, particularly regarding Canadian friends from outside the Arab culture, were given lower priority than extended family. In a qualitative study, Wannas-Jones (2003) likewise found that the family was prioritized above social relations, and that this was consistent among all Arabs, whether participating youth were Muslim or Christian.

Family and peer relations were significantly influential on participating newcomer youths' early integration experiences. Evin has shared that her elderly parents require her support primarily; she provides support by accompanying them to appointments and more. Her parents, however, encourage her to maintain peer relations both from her heritage culture and from the larger "Canadian society." However, Evin shared that they would generally prefer to be familiar with her acquaintances which she believes is their approach to supporting and protecting her. Reflecting on her parents' support, Evin states, "They are very supportive of me to engage in like ... new sports, volunteering, and education, everything ... everything to help me grow and succeed. They also helped me get my G1 and I'm now in driving school to do my G2." Similarly, Kheder supports his parents through interpretation and accompanying his family to several appointments; however, he asserts that he was able to maintain peer relations, yet devotes a shorter time to that due to his focus on academics and other youth engagement activities. Contradictory to their experiences, Naeem, being alone and separated from his family, shares that he longs for his family to join him as they are his primary support system.

\section{Education System as a Host Society}

The school system is a key component of Arab newcomer youth's resilience and progress towards effective integration. The education system is a 
powerful precursor to integration as the academic environment influences socialization through peer formation and further community engagement. Such an environment is vital in shaping newcomer youth experience of the host culture, as it is here that they acquire most of their knowledge and where most of their reflection on their settlement experience occurs (Behrens et al., 2015; Berry, 2006, 2013). Hence, educational experiences are important to discuss when speaking to Syrian newcomer youth; they would inform whether their experience was facilitative to or impeding their integration.

Both Kheder and Evin have shared their dreams of engaging in further academic studies, and how these were met with some discouragement within the school system. Both come with limited English language proficiency and both have been out of school for some time-period prior to immigrating to Canada. The message conveyed to them has been to focus on improving their English language and pursue dreams that are "more achievable." Kheder has shared with his Case Manager at the Multicultural Council of Windsor Essex (MCC) that his dream is to become a Civil Engineer: "I hope to become a Civil Engineer and I'm trying to get there. To be more specific, I would like to work in infrastructure." When asked about the reactions of his school, peers, the agency (MCC), and community regarding his academic and professional goal, he said that initially, there was some hesitation from the school system, primarily from teachers, on whether his goal is realistic. However, as his English language development progressed, the school and teachers have become more supportive of Kheder's educational aspirations. Kheder has mentioned that he continues to face some discouragement from his peers, stating that they have shared that, "this is difficult, we are newcomers, and this is not for us. I may be more confident than my peers, they may be scared to do what is required." Such response clearly conveys that there continues to be a need for our society to refrain from impeding potential achievement among youth and hold a true responsibility of being a supportive system. We are the gatekeepers to newcomers' full integration, and we need to continue acting as such.

In like manner, Evin and Naeem have shared similar experiences in their respective school systems, and both have shared advanced academic and career goals. Naeem was a nurse in his home country and was hoping to either engage in the same or a related field. Evin is completing her high school diploma this year and has shared that she would like to enroll in medical school to become a physician, possibly a surgeon. Both have shared 
similar instances where the response to their goals from the educational system and from the larger community is that, in reality, their goals may not be achievable.

All three youth have shared that their determination and persistence on the maintenance of their goals stems from two primary sources of social support: a public and a private source. Social support was examined in empirical research on Arab immigrants' adjustment. There are two life domains that could distinctively influence adjustment: a private and public life domain. Generally, support and well-being in the private domain, consisting of immediate family and individual experiences, results in better psychological adjustment (Paterson, 2008). In turn, support from the public life domain, consisting of the larger society, results in greater sociocultural adjustment (Paterson, 2008). All three youth have agreed that their families continue to be the greatest source of motivation. Additionally, their engagement in multiple efforts and the motivation and support they have received from settlement agencies, with special recognition to the MCC's workers, have been quite inspiring and greatly encouraging to continue advancing in their academics and career, respectively.

Naeem continues to engage in academic studies in areas of healthcare and nursing; he has also become a supportive figure himself to recent newcomers shortly after one-year of settling in Windsor. Evin, on the other hand, has made great progress in English and academia, and is working hard to achieve a higher grade point average so she can engage in pre-medical studies at the University of Windsor. Kheder is graduating high school this year and attending college next year to begin his academic journey. In 2017, Kheder created a model of a house that he showed to his Case Manager at MCC and with the school. The project was a personal effort that Kheder has created to put some of his interests in architecture and infrastructure into action. When asked about his inspiration, Kheder said, "I made it to prove to myself that I can do everything I want. That's why I did it all by myself. Because it's part of my dream to be in civil engineering, in that way, I provided to myself that I can achieve whatever I want." In recognition of the importance of MCC as a formal supportive system, the newcomer youth's effort was featured in the agency's Gazette of Winter, 2017 (see Figure 2). 
Khedr Al-Khalifa- CSS Client

Since his arrival on December 22nd, 2016, Khedr AlKhalifa has demonstrated significant interest and great motivation

to improve his language, excel

in academia, participate in civic engagement and reach his goals.

Khedr has been actively engaged in all youth activities organized by the MCC and other partnering agencies. He has been wonderfully working towards achieving his goals in multiple areas. In terms of language development, Khed has continuously practiced English with his surroundings, within the youth activities at MCC, and has dedicated a major part of his summer break to advance his English language with different resources. Khedr continues to excel in academia. Khedr's goal is to complete a degree in civil engineering at the University of Windsor or engage in architectural studies and potenfially work in the field. One significant achievement Khedr shared with the CSS Case Manager working with youth is the pictured model house that he built during summertime.

Khedr has put significant thought and effort into designing and building

the model house and is proud of his

achievement. Khedr has potential goals

of registering in school and obtaining part time employment.

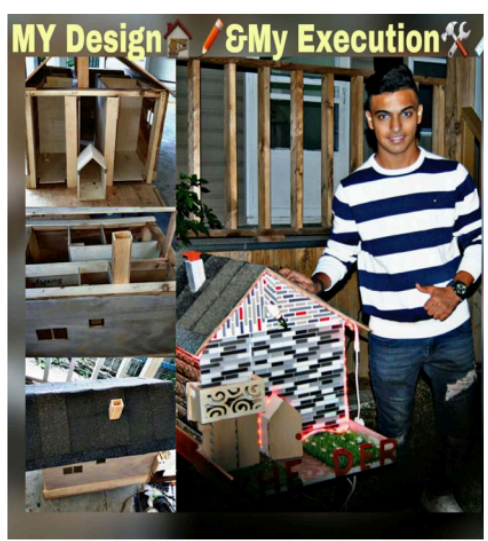

Figure 2.

Kheder Al

Khalifa

features his

built model

home: "My

Design, My

Execution"

Retrieved from: the Multicultural Council of Windsor Essex (www.themcc.com; link to the Winter 2017 Gazette; http://themcc.com/wpcontent/uploads/2017/12/Winter-2017.pdf)

To reconcile between the newcomer and Canadian experience, the MCC utilizes its gazettes and other social media forums as means to celebrate progress and success stories among its newcomer clientele, with special attention devoted to youth efforts and engagements in multiple programs. The next sections speak further to such engagements and their role in the enhancement of initial integration milestones among newcomer youth.

Peer relations were initially an element of great concern to newcomer youth in schools (Daniel, 2013; Wannas-Jones, 2003). Youth have reported that their separation from their Canadian peers through English as a Second Language were greatly ineffective in helping them establish positive relations with peers from their host society. First, they mentioned that they naturally resort to continuing to speak their native language, hindering their ability from advancing their English language proficiency. Being separated from their peers acts as a barrier from their ability to learn about and eventually adopt aspects of their new, host society. According to Berry (2013), the Multiculturalism Act of 1988 frames the interests and values 
placed on diversity in concrete terms as it confirms the composition of a Canadian society that is culturally and racially diverse. Consequently, we are a nation and society that foster integration as the adaptive and supported acculturation strategy (Behrens et al., 2015; Berry, 2013, 2014; Paterson, 2008). Due to their academic and English language advancement, contributing Syrian newcomer youth shared that they are content to have friends from all different cultures where they have the opportunity to celebrate their heritage and gain insight into other cultures. They have framed this as an avenue for English language advancement, maintenance and growth of their social network, and an experience that enhances their sense of belonging and consequent integration into their new Canadian community.

\section{Youth Engagement and Healing - an Integration Milestone}

Recognizing the primitive role that the host society plays in the healing and reconciliation of newcomer youth within our society, youth were asked to reflect on their engagement in programs and volunteerism as extracurricular efforts, and how influential these were to date in their settlement and integration experiences. Naeem has shared that without the encouragement of the settlement agencies and involvement in multiple opportunities at the MCC, the process of integrating into his new community may have been quite difficult. In his initial year here in Windsor, Naeem has been actively engaged in multiple events and programs where he was able to share his experience prior to and post immigrating to Canada. In a little over one year of him being in Canada, Naeem has become one of the C6 (Community, Connecting, Culture, Collaborating, Coaching, and Cooperating) matching program volunteers at the MCC. He supported recent newcomers to Canada by introducing them to programs and services he became familiar with, and where he supports MCC staff in facilitating important community engagement and recreational events for newcomer youth. Naeem has shared that this has helped him enhance his self-confidence and feel content that he was able to give back to his community who has been of great support since his arrival here in Canada. Naeem, like other Syrian youth, has fled his war-torn homeland searching for peace and to re-establish his personal

Facilitative Factors and Impediments to Newcomer Youth's Initial Integration Milestones | 254 
and professional life. Naeem brings great potential with him; he had the opportunity to share his gratitude for the supports that he received when speaking about his personal settlement experience at a City of Windsor forum. The forum entitled, "We Came Together," occurred in December of 2017 and was a great community forum for progress reports on Syrian Refugee Resettlement. Naeem was one of the panelists who shared his preimmigration and current integration milestones achieved through the supports received in their local Windsor-Essex community. Naeem urged agencies and service providers from different sectors to continue their active involvement with newcomer youth like him, for service providers are agents of hope for healing among youth with pre-immigration traumatic experiences. He shared that he believes that through supporting refugee youth in the new community to continue to prosper that social justice for them is attained. Achieving potential in his new Canadian society, as Naeem asserted, is the best response to undergoing violence, and is a proof that war and trauma can rather be agents of success and survival, rather than failure and despair.

Evin brings great potential for academic achievement and civic involvement, and has been actively engaged in youth engagement activities. She continues to be a key player in a variety of youth volunteerism and engagement activities at the MCC. Evin helps with the development and maintenance of the $\mathrm{C} 6$ youth Facebook page and she has supported staff in inviting clientele to different events. Within the Client Support Service (CSS) youth program, Evin has co-led and supported the session delivery, and had great contributions to local sub-council meetings. Evin has also successfully completed and received a Leadership Program certificate at a partnering settlement agency, Women Enterprise Skills Training (WEST). She has shared that she is thankful for these opportunities and believes that she has a significant contribution to make. These volunteer activities bring value to her experience and help her further integrate in her new community. Learn more about Evin's story in this short interview, where she shares more about her early integration experience, her happiness with her civic engagement in extracurricular activities and volunteerism, and what helps continue motivating her to progress. The link to the interview is below; in consent with Evin:

https://www.youtube.com/watch?v=cFPdN1GG53k\&feature=youtu.be

Kheder has shared his perspective on how integral his youth community engagements have been in shaping his early stages of integration. He has

255 | Facilitative Factors and Impediments to Newcomer Youth's Initial Integration Milestones 
participated primarily with the MCC's youth programs and services. Kheder has actively engaged in Client Support Services youth activities and events and has helped with delivery of partial components. He attended a workshop on Internet safety and cyber-bullying, contributed to the local sub-council meeting as one of the sub-council members, and has attended multiple events core to his learning and advancement. He also briefly worked within the construction field, something that he considers a great achievement as it is quite relevant to his field. At another partnering agency, the New Canadian Centre for Excellence (NCCE) in Windsor, Kheder helped with providing meals and other items to homeless people. On his engagements with the MCC, Kheder asserts, "MCC helped to encourage me to speak in English even in my house; speak English even with people who speak Arabic. I'm doing this to evolve my language." He mentioned that the encouragement to speak English even on field trips was very helpful to him. Additionally, trips such as the one to the University of Windsor Open House in March was an excellent supportive approach as it gave him an idea of, "where I'm going after school and which department, see how people deal with each other, and see different cultures. No one asked what is your business here? I was welcomed there. That encouraged me to advance my studies and probably attend university." The sense of welcome to all newcomer youth at that event was shared by all participating newcomer youth as one of the best experiences they have encountered for they did not feel different. They felt that they belong here.

All three youth have considered the ways in which their engagements have helped them to suppress their pre-immigration traumatic experiences with war and feel that their reestablishment and advancement is not only a light of hope, but also a reality. Evin shared that people in Canada do encourage her to enhance her socialization; she finds volunteering as something that makes her feel happy and confident, helps her meet new people, and expands her social network. She reflects further on this in her interview on how she finds it helpful for her early integration thus far. When asked to reflect on his involvements, Kheder states, "This made me feel that I'm a good citizen for Canada. I do whatever I can to make people happy. Canada encourages socializing and that's what I would like to do and be part of people here." Through shared experiences and perspectives of youth, we harness the potential of newcomer youth while facilitating their integration. 


\section{Social Justice in the Perspective of Newcomer Youth}

In alignment with Tikkun, a theme of healing, reconciliation, and social justice, it is inescapable to capture the conceptual meaning that social justice carries in the perspective of newcomer youth. When asked to define and reflect on social justice in the videotaped interview, Evin sees it in gender equality; she believed that nobody should be stripped of their right to education and advancement. She also sees it in the involvement of democratic decisions here in Canada. According to her, we have social justice here in Canada and "everyone uses it;" she believes that everyone is treated with respect and that there is "no different treatment for who you are and what you're doing." As for Kheder, he believes that social justice is already applied here; he sees it in the respectful and welcoming treatment in his Windsor community. He believes that he has equal rights like his youth encounters here in Canada in areas of education, employment, and active involvements in the community.

While Naeem agrees with both Kheder and Evin, he has an elevated fear as an Arab and Muslim youth. As empirical research demonstrates, associating September 11, 2001 and other terrorist attacks with religious and cultural beliefssubjects Arabs to a challenging acculturation experience (Akram, 2002; Awad,2010; Kumar,Warnke, \& Karabenick, 2014; Wannas-Jones, 2003). Arab youth have reported enhanced acculturative stress levels, challenges in developing their identity, and difficulty establishing peer relationships (Britto \& Amer, 2007; Daniel,2013; Shryock \& Howell, 2003; Wannas-Jones, 2003; Wrobel, Farrag, \& Hymes, 2009). Arab youth shared that one factor to elevated acculturative stress was the negative media portrayals of Arabs and Islam (Awad, 2010; Zafar \& Ross, 2015).In the correspondence with Naeem on social justice and full potential achievement, he shares that he fears that the media image would be an adopted response to his attempts to advance professionally and integrate more successfully herein Canada. While he feels that he is generally welcomed here, he senses that some community members may have preconceived images of him because of his background. He believes that as his network of support, we have the role as the host society to continue enhancing the larger society's knowledge about the potential that each of them bring with them, and the significant contributions that they would make to their respective communities provided that such opportunities are available for newcomer youth. 


\section{Conclusion}

In light of Tikkun, this book chapter has sought to seek further insight into the integration of Arab youth (primarily Syrian youth) and how the host society acts as a facilitative factor or impediment to the initial integration milestones. The chapter has consulted both theoretical knowledge and anecdotal evidence to speak about how newcomer youth's active engagement can lead to the healing of the traumatic encounter with war, to reconcile with the new community, and achieve social justice for newcomer youth. The chapter seeks to answer the following questions: How are Arab newcomer youth actively engaged in their community, and how does their involvement facilitate their integration and progressively lead to their healing and reconciliation? The chapter concluded with insight into the youth's perspectives on the meaning of social justice, and the ways in which they believe this is achieved in their new community in Canada. Thematically and anecdotally, it is evident that as the host community, we are the lead in making the reconciliation effectively achievable. Newcomer youth escaping war bring a lot of potential with them; it is our core responsibility as a society that believes in the power of diversity and harmony to foster these potentials and ensure they are not missed. We are in the position of power to ensure that healing and reconciliation are achieved, thus leading to a strongly attained socially-just society.

\section{References}

Akram, S. M. (2002). The aftermath of September 11, 2001: The targeting of Arabs and Muslims in America. Arab Studies Quarterly, 24 (2\&3), 61-118. Retrieved from https://www.jstor.org/stable/41858412 Awad, G. H. (2010). The impact of acculturation and religious identification on perceived discrimination for Arab/Middle Eastern Americans. Cultural Diversity \& Ethnic Minority Psychology, 16(1), 59-67. doi:10.1037/a0016675 Behrens, K., del Pozo, M. A., Großhennig, A., Sieberer, M., \& Graef-Calliess, I. T. (2015). How much orientation towards the host culture is healthy? Acculturation style as risk enhancement for depressive symptoms in 
immigrants.International Journal of Social Psychiatry,61(5), 498-505. doi:10.1177/0020764014560356

Berry, J. W. (2005). Acculturation: Living successfully in two cultures. International Journal of Intercultural Relations, 29(6), 697-712. doi:10.1016/ j.ijintrel.2005.07.013

Berry, J. W. (1992). Acculturation and adaptation in a new society. International Migration, 30(s1), 69-85. doi:10.1111/ j.1468-2435.1992.tb00776.x

Berry, J. W. (2001). A psychology of immigration. Journal of Social Issues ,57(3), 615-631. doi:10.1111/0022-4537.00231

Berry, J. W. (2008). Globalisation and acculturation. International Journal of Intercultural Relations, 32(4), 328-336. doi:10.1016/j.ijintrel.2008.04.001

Berry, J. W. (1997). Immigration, acculturation, and adaptation. Applied Psychology,46(1),5-34. doi:10.1111/j.1464-0597.1997.tb01087.x

Berry, J. W. (2006). Mutual attitudes among immigrants and ethno-cultural groups in Canada. International Journal of Intercultural Relations, 30, 719-734. doi:10.1016/j.ijintrel.2006.06.004

Berry, J. W. (2013). Research on multiculturalism in Canada.International Journal of Intercultural Relations,37(6), 663-675. doi:10.1016/ j.ijintrel.2013.09.005

Berry, J. W. (2014). Acculturation. In Grusec, J. E., \& Hastings, P. D. (Eds.) Handbook of socialization: Theory and research (pp. 520-549). Guilford Publications: United States.

Berry, J. W., \& Kalin, R. (1995). Multicultural and ethnic attitudes in Canada: An overview of the 1991 National Survey. Canadian Journal of Behavioural Science/Revue canadienne des sciences du comportement,27(3), 301. doi:10.1037/0008-400x.27.3.301

Berry, J. W., Kim, U., Power, S., Young, M., \& Bujaki, M. (1989). Acculturation attitudes in plural societies. Applied Psychology, 38(2), 185-206. doi:10.1111/ j.1464-0597.1989.tb01208.x

Berry, J. W., Phinney, J. S., Sam, D. L., \& Vedder, P. (2006a). Immigrant youth: Acculturation, identity and adaptation. Applied Psychology: An International Review, 55(3), 303-332. doi:10.1111/j.1464-0597.2006.00256.x Berry, J. W., Phinney, J. S., Sam, D. L., \& Vedder, P. (2006b). Immigrant youth in cultural transition: Acculturation, identity and adaptation across national contexts.New Jersey: Psychology Press.

Berry, J. W., \& Sabatier, C. (2010). Acculturation, discrimination, and adaptation among second generation immigrant youth in Montreal and

259 | Facilitative Factors and Impediments to Newcomer Youth's Initial Integration Milestones 
Paris. International Journal of Intercultural Relations, 34, 191-207. doi:10.1016/j.ijintrel.2009.11.007

Britto, P. R., \& Amer, M. M. (2007). An exploration of cultural identity patterns and the family context among Arab Muslim young adults in America. Applied Developmental Science, 11(3), 137-150. doi:10.1080/ 10888690701454633

Daniel, S. (2013). Immigrant and non-immigrant youth in Canada: Cultural orientation, ethnicity of friends, and life satisfaction among four ethnic groups (Master thesis). Retrieved from Library and Archives Canada (ISBN: 978-0-494-87354-0)

Hui, B. P. H., Chen, S. X., Leung, C. M., \& Berry, J. W. (2015).Facilitating adaptation and intercultural contact: The role of integration and multicultural ideology in dominant and non-dominant groups. International Journal of Intercultural Relations, 45, 70-84. doi:10.1016/ j.ijintrel.2015.01.002

Immigration, Refugees and Citizenship Canada. (2017, November 1). Retrieved from https://www.canada.ca/en/immigration-refugees-citizenship/ news/notices/supplementary-immigration-levels-2018.html

Kumar, R., Warnke, J. H., \& Karabenick, S. A. (2014). Arab-American male identity negotiations: Caught in the crossroads of ethnicity, religion, nationality and current contexts.Social Identities, 20(1), 22-41. doi:10.1080/ $\underline{13504630.2013 .864464}$

Laxer, E. (2013). Integration discourses and the generational trajectories of civic engagement in multi-nation states: A comparison of the Canadian provinces of Quebec and Ontario. Journal of Ethnic and Migration Studies, 39(10), 1577-1599. doi:10.1080/1369183x.2013.815432

Migration Policy Institute. (2015). Retrieved from http://www.migrationpolicy.org/programs/data-hub/internationalmigration-statistics

Multicultural Council of Windsor Essex. (n.d.). Retrieved from http://themcc.com/

Ng, E. S., \& Bloemraad, I. (2015). A SWOT analysis of multiculturalism in Canada, Europe, Mauritius, and South Korea.American Behavioral Scientist, 59(6), 619-636. doi:10.1177/0002764214566500

Ng, E. S., \& Metz, I. (2015). Multiculturalism as a strategy for national competitiveness: The case for Canada and Australia.Journal of Business Ethics,128(2), 253-266. doi:10.1007/s10551-014-2089-8

Palmer, D. L. (1996). Determinants of Canadian attitudes toward immigration:

Facilitative Factors and Impediments to Newcomer Youth's Initial Integration Milestones | 260 
More than just racism? Canadian Journal of Behavioural Science, 28(3), 180-192. doi:10.1037/0008-400X.28.3.180

Paterson, A. D. (2008). The private and public life domains of Arab youth in Canada: Acculturation, ethnic identity, social support, and adjustment (Master thesis). Retrieved from Library and Archives Canada. (ISBN: 978-0-494-47080-0)

Sam, D. L., \& Berry, J. W. (2010). Acculturation: When individuals and groups of different cultural backgrounds meet. Perspectives on Psychological Science, 5(4), 472-481. doi:10.1177/1745691610373075

Sabatier, C., \& Berry, J. W. (2008).The role of family acculturation, parental style, and perceived discrimination in the adaptation of second-generation immigrant youth in France and Canada. European Journal of Developmental Psychology, 5(2), 159-185. doi:10.1080/17405620701608739

Sam, D. L., Vedder, P., Liebkind, K., Neto, F., \& Virta, E. (2008). Immigration, acculturation and the paradox of adaptation in Europe. European Journal of Developmental Psychology,5(2), 138-158. doi:10.1080/17405620701563348

Shryock, A., \& Howell, S. (2003). Cracking down on diaspora: Arab Detroit and America's "war on terror". Anthropological Quarterly, 76(3), 443-462. doi:10.1353/anq.2003.0040

Vineberg, R. (2011). Continuity in Canadian immigration policy 1947 to present: Taking a fresh look at Mackenzie King's 1947 immigration policy statement. Journal of International Migration and Integration/Revue de l'integration et de la migration internationale,12(2), 199-216. doi:10.1007/ s12134-011-0177-5

Wannas-Jones, J. (2003). Globalization and the reconciliation of dissonant hybrididentities: A case study of Canadian-Arab youths (Doctoral dissertation). Retrieved from National Library of Canada. (ISBN: 0-612-88063-X)

Welcome to Windsor Essex. (n.d.). Retrieved from https://www.welcometowindsoressex.ca/en/why-windsor-essex/ immigration-statistics.asp

Wrobel, N. H., Farrag, M. F., \& Hymes, R. W. (2009). Acculturative stress and depression in an elderly Arabic sample.Journal of Cross-Cultural Gerontology,24(3), 273-290. doi:10.1007/s10823-009-9096-8

Zafar, S., \& Ross, E. C. (2015). Interreligious contact, attitudes, and stereotypes: A study of five religious groups in Canada.Canadian Journal of Behavioural Science/Revue canadienne des sciences du comportement, 47(1), 37. doi:10.1037/a0036720

261 | Facilitative Factors and Impediments to Newcomer Youth's Initial Integration Milestones 
"This book chapter is an independent writing and is in contribution to the Tikkun Youth Project (Healing, Reconciliation and Advocacy for Social Justice)" 